04,06,09

\title{
Фотолюминесценция ниобата лития, легированного медью
}

\author{
(C) В.С. Горелик ${ }^{1,2}$, А.Ю. Пятышев ${ }^{2,3}$, Н.В. Сидоров ${ }^{4}$ \\ ${ }^{1}$ Физический институт им. П.Н. Лебедева РАН, \\ Москва, Россия \\ ${ }^{2}$ Московский государственный технический университет им. Н.Э. Баумана, \\ Москва, Россия \\ ${ }^{3}$ АО „НПП „Исток“ им. Шокина“, \\ Фрязино, Россия \\ ${ }^{4}$ Институт химии и технологии редких элементов и минерального сырья им. И.В. Тананаева Кольского НЦ РАН, \\ Апатиты, Россия \\ E-mail: gorelik@sci.lebedev.ru
}

(Поступила в Редакцию 24 ноября 2017 г.)

\begin{abstract}
Зарегистрированы спектры фотолюминесценции монокристалла ниобата лития, легированного медью при возбуждении светодиодами видимого и ультрафиолетового диапазонов, а также импульсно-периодическим лазером с длиной волны генерации $266 \mathrm{~nm}$. При резонансном возбуждении светодиодом с длиной волны $527 \mathrm{~nm}$ наблюдалось резкое возрастание (на два порядка) интенсивности фотолюминесценции. При возбуждении светодиодом с длиной волны $467 \mathrm{~nm}$ обнаружены многофонноные повторения в спектре фотолюминесценции в спектральном диапазоне $520-620 \mathrm{~nm}$.
\end{abstract}

Работа выполнена при поддержке РФФИ (грант № 16-52-00026 Бел_а) и БРФФИ (грант Ф16Р-063).

DOI: $10.21883 /$ FTT.2018.05.45784.339

Сегнетоэлектрические кристаллы ниобата лития [1-4] находят широкое применение в различных электро- и акустооптических устройствах, а также используются как активные компоненты в нелинейной оптике. Ряд свойств этих кристаллов зависит от присутствия структурных дефектов, возникающих при росте кристалла или под действием внешних излучений [5-7]. Поэтому исследование оптических свойств кристаллов ниобата лития с различными примесями и дефектами является актуальной задачей. В частности, представляет интерес установление возможности управления оптическими и электрическими свойствами ниобата лития путем его легирования различными ионами $[8,9]$. Введение в ниобат лития примесных центров с электронными переходами в видимой области спектра $(\mathrm{Fe}, \mathrm{Cu})$ позволяет реализовать резонансное воздействие на такие кристаллы излучением видимого диапазона. При этом открываются возможности для повышения интенсивности сигнала фотолюминесценции, а также для эффективного возбуждения инфракрасно-активных мод кристаллической решетки ниобата лития.

Фотолюминесценцию стехиометрического кристалла ниобата лития ранее [10] удалось наблюдать в синей области спектра только при низких температуpax $(4.2 \mathrm{~K})$, при возбуждении ультрафиолетовыми источниками. Спектр имел вид широкой полосы с максимумом около $450 \mathrm{~nm}$. Легирование ниобата лития ионами железа $\left(\mathrm{Fe} 2^{+}\right)$приводит к смещению максимума спектра фотолюминесценции нелегированного кристалла из синей области в красную со сдвигом на $200 \mathrm{~nm}$. При этом интенсивность люминесценции пропорциональна концентрации ионов железа $[11,12]$.
Легирование ионами хрома $\left(\mathrm{Cr}^{3+}\right)$ приводит к интенсивной фотолюминесценции в красной области спектра [13]. Было показано, что форма и относительная интенсивность каждой полосы в спектре люминесценции зависит от концентрации ионов хрома и внутренних дефектов кристалла. Установлено, что в спектре фотолюминесценции ниобата лития, легированного ионами тербия $\left(\mathrm{Tb}^{3+}\right)$, наблюдается безызлучательная релаксация состояний ${ }^{5} \mathrm{D}_{3}$ в ${ }^{5} \mathrm{D}_{4}$ и интенсивная полоса излучения с максимумом $550 \mathrm{~nm}$ [14]. Легирование ниобата лития ионами эрбия $\left(\mathrm{Er}^{3+}\right)$ приводит к появлению двух интенсивных полос люминесценции в ИКобласти (1010 и $1500 \mathrm{~nm})$ [15]. Обнаружено [16], что легирование ионами магния $\left(\mathrm{Mg}^{2+}\right)$ кристаллов ниобата лития, содержащих примеси ионов тулия $\left(\mathrm{Tm}^{3+}\right)$ и эрбия $\left(\mathrm{Er}^{3+}\right)$, не влияет на спектральное положение максимумов интенсивности фотолюминесценции. При анализе спектров люминесценции кристалла ниобата лития, легированного ионами эрбия $\left(\mathrm{Er}^{3+}\right)$ и иттербия $\left(\mathrm{Yb}^{3+}\right)$, установлено, что наличие парных центров может привести к существенному изменению времени жизни возбуждения в примесной системе кристалла [17]. За счет добавления ионов калия $\left(\mathrm{K}^{+}\right)$к ниобату лития, легированному гольмием $\left(\mathrm{Ho}^{3+}\right)$ и иттербием $\left(\mathrm{Yb}^{3+}\right)$, удается увеличить сигнал люминесценции кристалла в зеленой области спектра в 20 раз [18].

В настоящей работе впервые сообщается о наблюдении интенсивной фотолюминесценции при комнатной температуре в монокристаллах ниобата лития, легированных медью, при использовании в качестве источников возбуждающего излучения различных источников света ультрафиолетового и видимого диапазонов. 
При комнатной температуре ниобат лития находится в полярной фазе и является одноосным оптически отрицательным кристаллом. Точечная группа симметрии этого кристалла $\mathrm{C}_{3 v}$ не содержит центра инверсии; пространственная группа $\mathrm{C}_{3 v}^{6}(R 3 c)$ относится к ромбоэдрической сингонии. При этом параметры элементарной ячейки имеют следующие значения: $a=5.15 \AA, c=13.86 \AA$ и $\alpha=55^{\circ} 53^{\prime}$ [2,19]. В примитивной ячейке содержится две формульные единицы $\mathrm{LiNbO}_{3}$. При температуре $T_{c}=1483 \mathrm{~K}$ в этом кристалле происходит сегнетоэлектрический фазовый переход в неполярную (параэлектрическую) фазу, пространственная группа симметрии которой $-D_{3 d}^{6}(R \overline{3} c)$. В соответствии с результатами теоретико-группового анализа, представления вектора $\mathbf{V}$, псевдовектора $\tilde{V}$ и оптического представления $T_{\text {opt, }}$, классифицирующего фундаментальные моды кристаллической решетки, для сегнетоэлектрической фазы ниобата лития соответственно имеют вид [20]

$$
\begin{gathered}
\tilde{V}=A_{2}+E ; \quad V=A_{1}(z)+E ; \\
T_{\mathrm{opt}}=4 A_{1}(z)+9 E+5 A_{2} .
\end{gathered}
$$

Монокристаллы ниобата лития выращивались в воздушной атмосфере методом Чохральского [21,22]. Образец для исследований имел вид прямоугольного параллелепипеда с заданным направлением сегнетоэлектрической оси $Z$, соответствующей наибольшей стороне прямоугольника. В результате был выращен конгруэнтный кристалл ниобата лития с примесью меди $\mathrm{Cu}^{+}$с весовой концентрацией 0.043 mass. \%. Выращенные кристаллы имели красно-желтый цвет [23,24].

Возбуждение спектров фотолюминесценции (ФЛ) в исследуемом кристалле осуществлялось четвертой гармоникой $(266 \mathrm{~nm})$ лазера YAG : $\mathrm{Nd}^{3+}$ и полупроводниковыми светодиодами с длинами волн 369, 385, 410, 467 и $527 \mathrm{~nm}$. Принципиальные схемы экспериментальных установок приведены на рис. 1 и 2.

Возбуждающее излучение, выходящее из лазера или светодиода, фокусировалось линзой на вход кварцевого световода. Лазер на алюмоиттриевом гранате генерировал импульсно-периодическое излучение с длиной волны $266 \mathrm{~nm}$, шириной линии генерации $3 \mathrm{~nm}$, со средней мощностью генерации $10 \mathrm{~mW}$, с частотой следования импульсов $3 \mathrm{kHz}$ при их длительности $10 \mathrm{~ns}$. Пиковая плотность мощности возбуждающего ультрафиолетового излучения на поверхности монокристалла составляла $10^{5} \mathrm{~W} / \mathrm{cm}^{2}$. Средняя мощность генерации светодиодов составляла $20 \mathrm{~mW}$, ширина линии генерации $20 \mathrm{~nm}$. При помощи световодов (см. рис. 1 и 2) возбуждающее излучение подводилось к исследуемому образцу. Вторичное излучение (фотолюминесценция) при помощи других световодов направлялось на входную щель миниспектрометра FSD-8 и передавалось на компьютер для анализа. Возбуждающее и вторичное излучения распространялись в направлении сегнетоэлектрической оси исследуемого монокристалла.

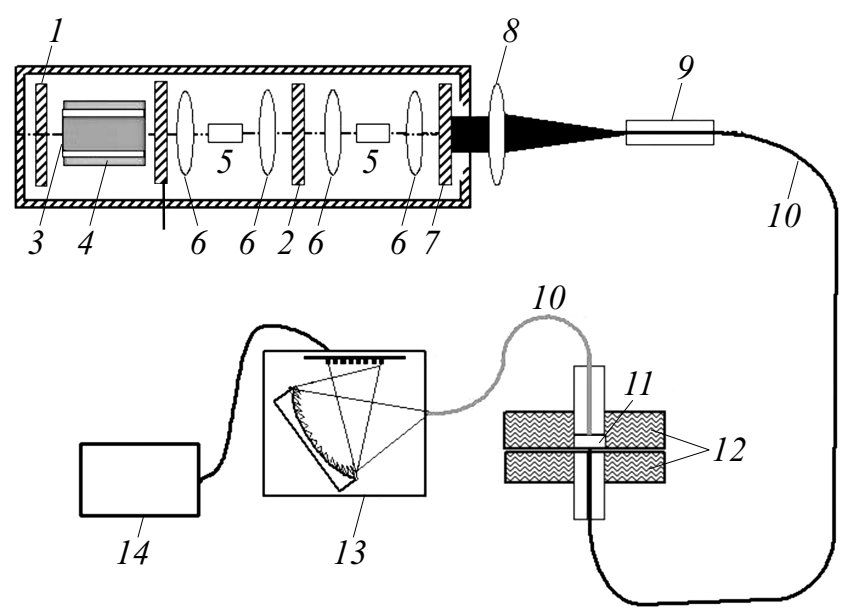

Рис. 1. Схема „на просвет“ для регистрации спектров ФЛ с использованием четвертой гармоники лазера $\mathrm{YAG}: \mathrm{Nd}^{3+}$ $(\lambda=266 \mathrm{~nm}): 1,2,7$ - диэлектрические зеркала; 3 - активный элемент лазера; $4-$ светодиоды „накачки“; $5-$ нелинейно-оптические кристаллы; 6,8 - линзы; 9 - фиксатор световода (кварцевого волокна); 10 - световод; $11-$ ориентированный кристалл ниобата лития; 12 - кювета; 13 - миниспектрометр FSD-8; 14 - компьютер.
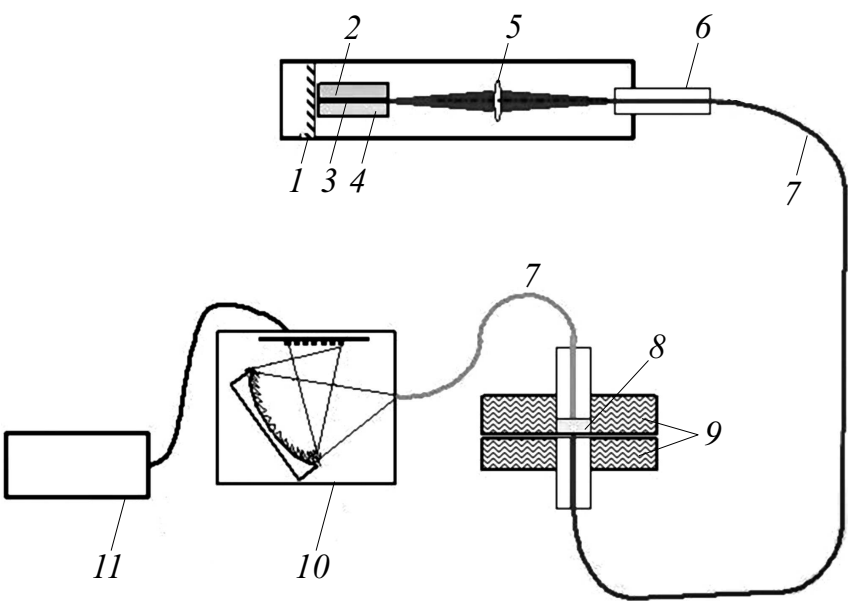

Рис. 2. Схема „на просвет“ для регистрации спектров ФЛ с использованием полупроводниковых светодиодов: 1 - диэлектрическое зеркало; 2-4 - полупроводниковый светодиод; 5 - линза; 6 - фиксатор свтовода (кварцевого волокна); 7 - световод; 8 - ориентированный кристалл ниобата лития; 9 - кювета; 10 - миниспектрометр FSD-8; 11 - компьютер.

Рис. 3 иллюстрирует вид зарегистрированных спектров ФЛ в кристаллах ниобата лития, легированных медью с концентрацией 0.043 mass.\%. Пунктиром приведен схематический спектр излучения лазера или светодиодов.

Как видно из рис. 3, при возбуждении фотолюминесценции коротковолновым излучением с длинами волн $(266,369,385$ и $410 \mathrm{~nm})$ спектр ФЛ имеет вид широкой полосы. При возбуждении ФЛ светодиодом с длиной 

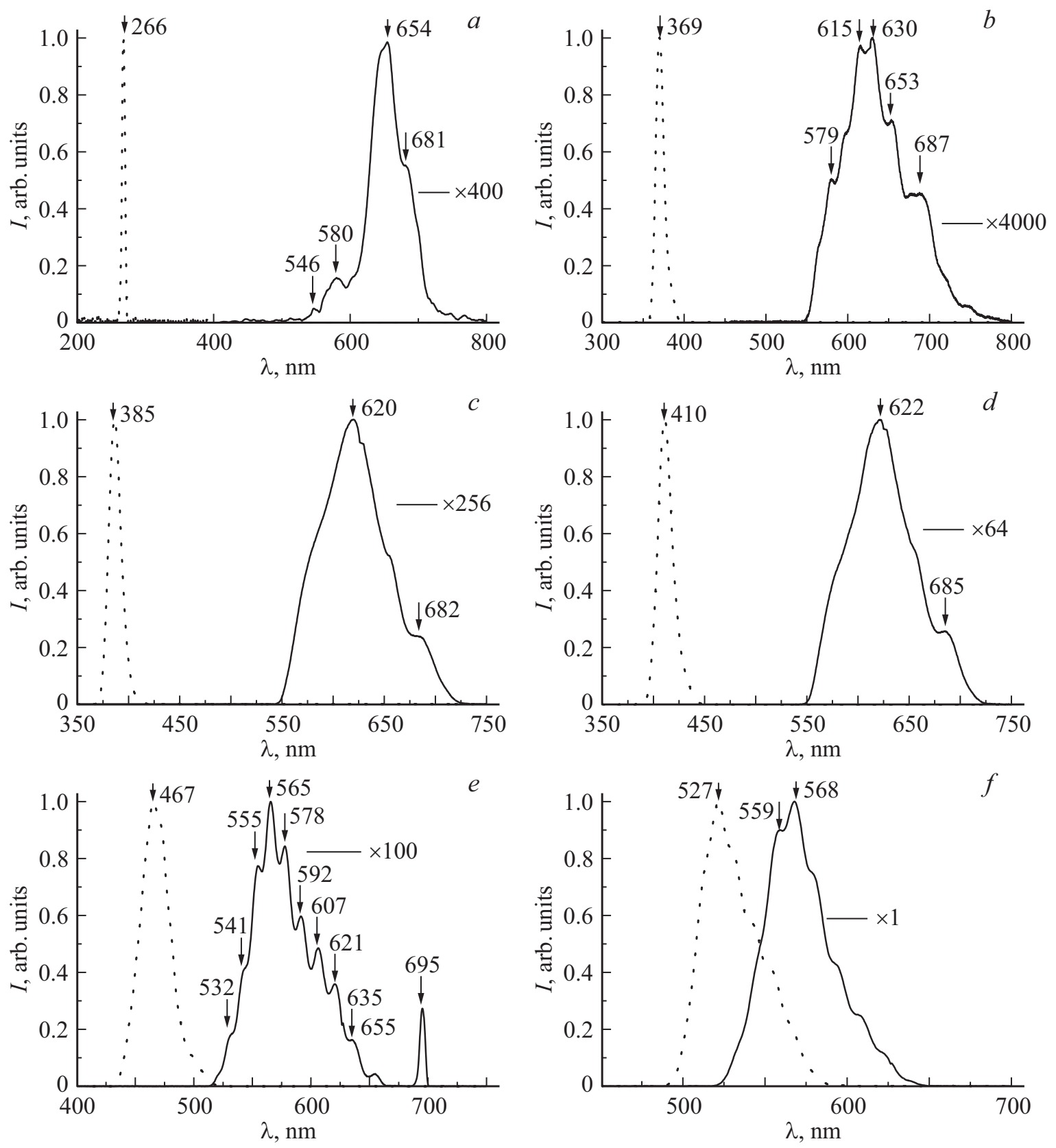

Рис. 3. Спектры фотолюминесценции в кристаллах ниобата лития, легированных медью при возбуждении различными источниками излучения: $a-\lambda=266 \mathrm{~nm}$ (четвертая гармоника твердотельного лазера); $b-\lambda=369 \mathrm{~nm}$ (полупроводниковый светодиод); $c-\lambda=385 \mathrm{~nm}$ (полупроводниковый светодиод); $d-\lambda=410 \mathrm{~nm}$ (полупроводниковый светодиод); $e-\lambda=467 \mathrm{~nm}$ (полупроводниковый светодиод); $f-\lambda=527 \mathrm{~nm}$ (полупроводниковый светодиод).

волны $467 \mathrm{~nm}$ форма спектра фотолюминесценции переходит от континуальной к дискретной. Таким образом, форма спектра ФЛ оказалась зависящей от длины волны возбуждающего излучения. Наибольшая интенсивность спектра ФЛ соответствует резонансному возбуждению $(\lambda=527 \mathrm{~nm})$. При переходе к коротковолновому возбуждению интенсивность ФЛ резко падала (см. рис. $3, a-f)$. С увеличением длины волны возбуждающего излучения максимум спектра фотолюминесценции смещался в сторону более коротких длин волн.
При возбуждении ФЛ светодиодом с длиной волны $467 \mathrm{~nm}$ (см. рис. 3,e) в спектре полосы ФЛ обнаруживаются множественные резкие пики. В таблице приведены длины волн, соответствующие этим пикам, и спектральные сдвиги $\Delta$. Модуль среднего значения спектрального сдвига составляет: $|\bar{\Delta}|=390.6 \mathrm{~cm}^{-1}$. Точность определения спектральных сдвигов $\Delta$ (см. таблицу) составляет $\pm 50 \mathrm{~cm}^{-1}$. В соответствии с результатами анализа спектров комбинационного рассеяния $[20,25-30]$ соответствующие фононы (см. таблицу) относятся к $2 A_{1}(z)$ 
и $3 A_{1}(z)$ инфракрасно-активным модам. Номера 2 и 3 соответствуют второй и третьей фундаментальным модам типа $A_{1}$.

На основе использования модели одного полярного осциллятора, соответствующего примесному экситону иона меди, приведем вид дисперсионных кривых поляритонных волн в обсуждаемом кристалле. Закон дисперсии поляритонов находится из соотношения:

$$
\omega^{2}=\frac{c_{0}^{2} k^{2}}{\varepsilon(\omega)}
$$

где диэлектрическая проницаемость $\varepsilon(\omega)$ обусловлена вкладом полярных мод кристаллической решетки, а также полярной моды примесного центра, приводящего к поглощению в видимой области спектра. Ограничимся учетом только одной резонансной частоты, соответствующей поглощению примесным экситоном в видимой области спектра. При этом диэлектрическая проницаемость принимает вид

$$
\varepsilon(\omega)=\varepsilon_{\infty} \frac{\omega_{l}^{2}-\omega^{2}}{\omega_{0}^{2}-\omega^{2}} .
$$

Здесь $\varepsilon_{\infty}$ - высокочастотная диэлектрическая постоянная, $\omega=\left(2 \pi c_{0}\right) / \lambda=2 \pi c_{0} v, \omega_{0}, \omega_{l}-$ круговые частоты поперечной и продольной примесной моды соответственно. Подставляя (3) в (2) получаем уравнение для дисперсионных кривых поляритонов

$$
\omega^{4}-\omega^{2} \frac{\omega_{l}^{2} \varepsilon_{\infty}+c_{0}^{2} k^{2}}{\varepsilon_{\infty}}+\frac{\omega_{0}^{2} c_{0}^{2} k^{2}}{\varepsilon_{\infty}}=0 .
$$

В результате решение для двух поляритонных ветвей имеет вид

$$
\omega_{ \pm}^{2}(k)=\frac{\omega_{l}^{2}+c^{2} k^{2}}{2}\left(1 \pm \sqrt{1-\frac{4 \omega_{0}^{2} c^{2} k^{2}}{\left(\omega_{l}^{2}+c^{2} k^{2}\right)^{2}}}\right) .
$$

Здесь $c^{2}=\frac{c_{0}^{2}}{\varepsilon_{\infty}}$. С учетом значения длин волн резонансного поглощения примесного экситона $\left(\lambda_{0}=525 \mathrm{~nm}\right)$ и

Длины волн, соответствующие максимумам спектра ФЛ на рис. 3,e, и спектральные сдвиги $\Delta$ между ними. Здесь $\lambda_{i}$ - длина волны максимума интенсивности в спектре ФЛ

\begin{tabular}{l|c|c|c|c|c}
\hline$i$ & $\begin{array}{c}\lambda_{i}, \\
\mathrm{~nm}\end{array}$ & $\begin{array}{c}\lambda_{i-1}, \\
\mathrm{~nm}\end{array}$ & $\begin{array}{c}\frac{1}{\lambda_{i}}, \\
\mathrm{~cm}^{-1}\end{array}$ & $\begin{array}{c}\frac{1}{\lambda_{i-1}}, \\
\mathrm{~cm}^{-1}\end{array}$ & $\begin{array}{c}\Delta=\frac{1}{\lambda_{i}}-\frac{1}{\lambda_{i-1}} \\
\mathrm{~cm}^{-1}\end{array}$ \\
\hline 1 & 532.4 & & 18782.9 & & \\
2 & 541.4 & 532.4 & 18470.6 & 18782.9 & -312.3 \\
3 & 554.6 & 541.4 & 18031.0 & 18470.6 & -439.6 \\
4 & 565.4 & 554.6 & 17686.6 & 18031.0 & -344.4 \\
5 & 577.8 & 565.4 & 17307.0 & 17686.6 & -379.6 \\
6 & 591.6 & 577.8 & 16903.3 & 17307.0 & -403.7 \\
7 & 606.6 & 591.6 & 16485.3 & 16903.3 & -418.0 \\
8 & 620.6 & 606.6 & 16113.4 & 16485.3 & -371.9 \\
9 & 635.4 & 620.6 & 15738.1 & 16113.4 & -375.3 \\
10 & 655.0 & 635.4 & 15267.2 & 15738.1 & -470.9
\end{tabular}

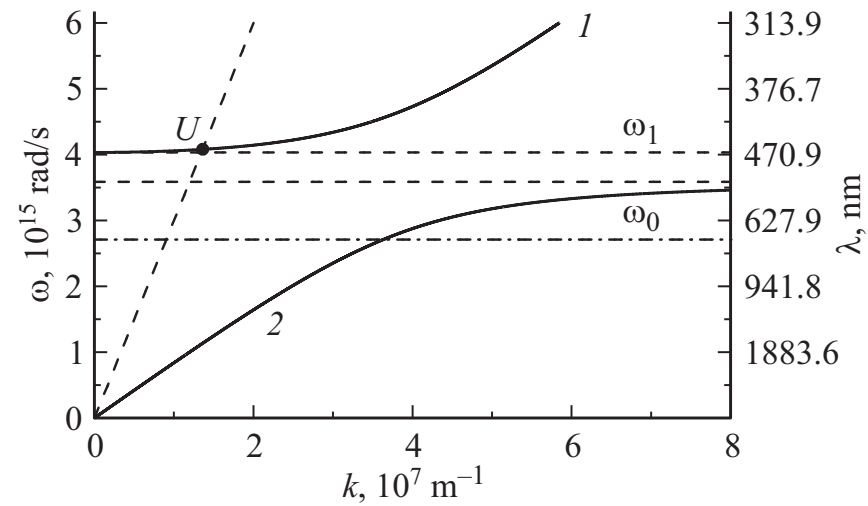

Рис. 4. Поляритонные кривые полярного осциллятора, соответствующего примесному экситону иона меди.

максимального пропускания в спектре ФЛ $\left(\lambda_{l}=467 \mathrm{~nm}\right.$; см. рис. $3, f)$ используем следующие значения величин для построения дисперсионных кривых поляритонов: $\omega_{0}=3.588 \cdot 10^{15} \mathrm{rad} / \mathrm{s} ; \quad \omega_{l}=1.12 \omega_{0}=4.033 \cdot 10^{15} \mathrm{rad} / \mathrm{s}$; $\varepsilon_{\infty}=10$. На рис. 4 приведены соответствующие поляритонные кривые, построенные с использованием уравнения (5). На этом рисунке приведены также значения $\omega_{0}$, $\omega_{l}$ и дисперсионная зависимость $\omega=c_{0} k$ (пунктиром), соответствующая закону дисперсии для фотонов в вакууме. При этом на рисунке штрих-пунктирной линией отмечено положение линии $695 \mathrm{~nm}$.

Точка $U$ соответствует пересечению прямой $\omega=c_{0} k$ и верхней дисперсионной ветви поляритонов. Ее координаты имеют значения: $k=1.361 \cdot 10^{7} \mathrm{~m}^{-1}$ и $\omega=4.08 \cdot 10^{15} \mathrm{rad} / \mathrm{s}$, что соответствует длине волны $461.7 \mathrm{~nm}$. В этой точке показатель преломления равен единице и пропускание кристалла является максимальным.

Групповая скорость поляритонов, с учетом (4), может быть определена из следующего соотношения:

$$
\begin{aligned}
V_{g r} & =\frac{d \omega}{d k}=\frac{c^{2} k\left(\omega^{2}-\omega_{0}^{2}\right)}{2 \omega^{3}-\omega\left(\omega_{l}^{2}+c^{2} k^{2}\right)} \\
& =\frac{c_{0}\left(\omega^{2}-\omega_{0}^{2}\right)^{2}}{\omega^{4}-\omega_{0}^{2}\left(2 \omega^{2}-\omega_{l}^{2}\right)} \sqrt{\frac{\omega^{2}-\omega_{l}^{2}}{\varepsilon_{\infty}\left(\omega^{2}-\omega_{0}^{2}\right)}} .
\end{aligned}
$$

На рис. 5 и 6 представлены зависимости групповых скоростей поляритонов от волнового вектора и круговой частоты для верхней и нижней ветвей (кривые 1 и 2 соответственно), вычисленные с использованием соотношения (6).

На этих же рисунках приведены значения $\omega_{0}, \omega_{l}$ и скорость света в вакууме $c_{0}$ (пунктиром). Как видно из рис. 5 и 6, в точке, соответствующей унитарному поляритону (точка $U$ ), групповая скорость поляритонов очень мала $\left(V_{g r}=7.366 \cdot 10^{6} \mathrm{~m} / \mathrm{s}\right)$.

Таким образом, анализ спектров фотолюминесценции в кристаллах ниобата лития, легированных медью, показал, что при возбуждении ФЛ коротковолновым 


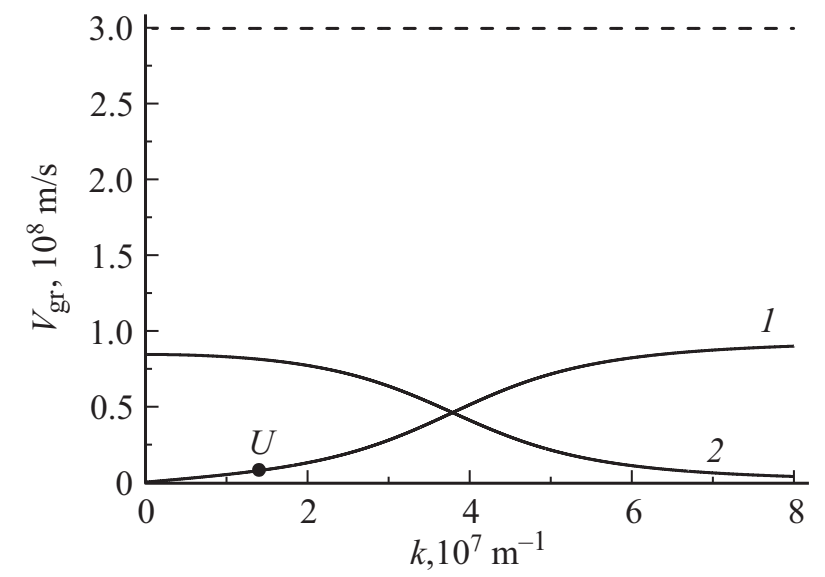

Рис. 5. Зависимость групповой скорости поляритонов от волнового вектора: 1 соответствует верхней поляритонной ветви, 2 - нижней поляритонной ветви рис. 4.

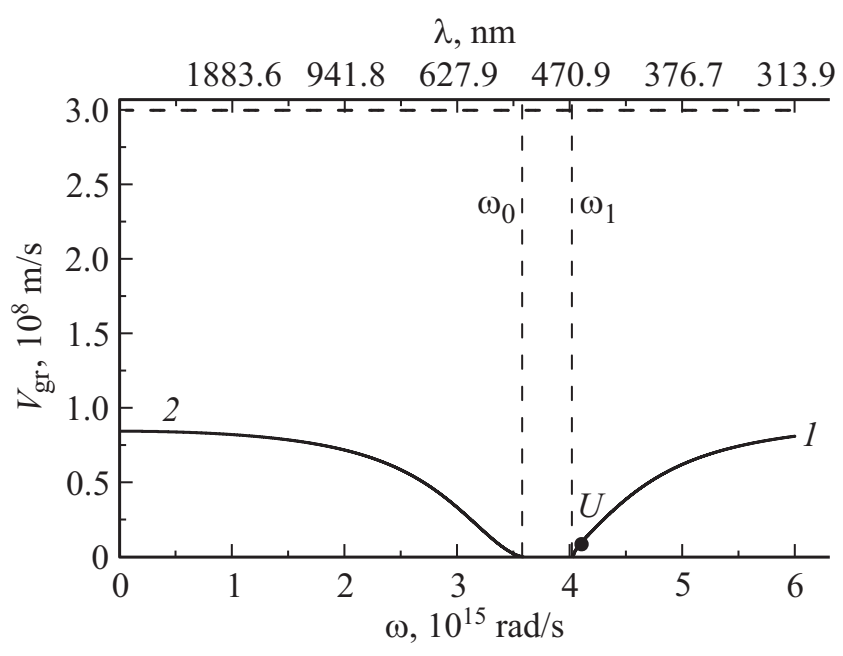

Pис. 6. Зависимость групповой скорости поляритонов от круговой частоты: 1 соответствует верхней поляритонной ветви, 2 - нижней поляритонной ветви рис. 4.

излучением $(266,369,385,410$ и $467 \mathrm{~nm})$ в видимой области спектра обнаруживается многофононное вторичное излучение, соответствующее резонансной комбинационной опалесценции с возбуждением полярных фононов. Так как соответствующая мода $A_{1}(Z)$ являются инфракрасно-активной, наблюдаемый эффект представляет интерес для создания источников терагерцового электромагнитного излучения при возбуждении ФЛ в кристаллах ниобата лития, легированных медью, источниками видимого и ультрафиолетового диапазонов. Аномальное замедление групповой скорости поляритонной волны на частоте унитарного поляритона представляет интерес для когерентного возбуждения поляритонных состояний, для реализации бозе-эйнштейноской конденсации экситонных поляритонов верхней ветви $[31,32]$, для наблюдения процессов двухфотонного поглоще- ния [33], а также для формирования связанных состояний поляритонов в диэлектрической среде [34-36].

\section{Список литературы}

[1] S.C. Abrahams, J.M. Reddy, J.L. Bernstein. J. Phys. Chem. Solids 27, 997 (1966).

[2] J.G. Bergman, A. Ashkin, A.A. Ballman, J.M. Dziedzic, H.J. Levinstein, R.G. Smith. Appl. Phys. Lett. 12, 92 (1968).

[3] R.S. Weis, T.K. Gaylord. Appl. Phys. A 37, 191 (1985).

[4] A.S. Barker, R. Loudon. Phys. Rev. 158, 433 (1967).

[5] O.F. Schirmer, O. Thiemann, M.J. Wohlecke. J. Phys. Chem. Solids 52, 185 (1991).

[6] T. Volk, M. Wöhlecke. Lithium Niobate. Defects. Photo refraction and Ferroelectric Switching. Springer (2008). 250 p.

[7] P. Günter, J.P. Huignard. Photorefractive Materials and Their Applications. Springer (2006). 426 p.

[8] N.V. Kukhtarev, T.V. Kukhtereva, G. Stargell, J.C. Wang. J. Appl. Phys. 106, 014111 (2009).

[9] X. Zhang, J. Wang, B. Tang, X. Tan, R.A. Rupp, L. Pan, Y. Kong, Q. Sun, J. Xu. Opt. Express 17, 9981 (2009).

[10] M.H.J. Emond, M. Wiegel, G. Blasse, R. Feigelson. Mater. Res. Bull. 28, 1025 (1993).

[11] R. Parsons, W.D. Cornish, L. Young. Appl. Phys. Lett. 27, 654 (1975).

[12] A. Harhira, L. Guilbert, P. Bourson, H. Rinnert. Appl. Phys. B 92, 555 (2008).

[13] F. Lhommeyk, P. Boursony, M.D. Fontanay, G. Malovichkoyz, M. Ailleriey, E. Kokanyanx. J. Phys.: Condens. Matter. 10, 1137 (1998).

[14] M. Lee, K.-S. Lim, S.-K. Lee, V.-T. Pham, K. Kitamura, S. Takekawa. J. Lumin. 102-103, 644 (2003).

[15] E.P. Kokanyan, G.G. Demirkhanyan, E. Steveler, H. Rinnert, M. Aillerie. Int. J. Mod. Phys. Conf. Ser. 15, 76 (2012).

[16] T. Tsuboi, S.M. Kaczmarek, Y. Nakai, W. Huang. J. Lumin. 149, 99 (2014).

[17] P.H. Muzhikyan. J. Contemp. Phys. 46, 17 (2011).

[18] R. Wang, Z. Liu, Y. Li. Spectrosc. Lett. 50, 394 (2017).

[19] Y. Shiozaki, T. Mitsui. J. Phys. Chem. Solids 24, 1057 (1963).

[20] В.С. Горелик, П.П. Свербиль. Неорган. материалы 51, 1190 (2015).

[21] Y. Zhang, Y.H. Xu, M.H. Li, Y.Q. Zhao. J. Cryst. Growth 233, 537 (2001).

[22] M.N. Palatnikov, N.V. Sidorov, A.A. Yanichev, A.A. Gabain, A.A. Kruk, K.Ya. Bormanis, V.Ya. Shur. Ferroelectrics 462, 80 (2014).

[23] A.K. Petrosyan, R.M. Khachatryan, E.G. Sharoyan. Phys. Status. Solidi B 122, 725 (1984).

[24] S. Kaczmarek. Ferroelectrics 256, 175 (2001).

[25] W.D. Johnston. Jr. Phys. Rev. B 1, 3494 (1970).

[26] В.С. Горелик, О.Г. Золотухин, М.М. Сущинский. ФТТ 22, 1024 (1980).

[27] Н.В. Сидоров, М.Н. Палатников, А.А. Яничев, А.А. Габаин, О.Ю. Пикуль, А.Н. Смирнов. Оптика и спектроскопия 115, 597 (2013).

[28] Н.В. Сидоров, А.А. Крук, А.А. Яничев, М.Н. Палатников, Б.Н. Маврин. Оптика и спектроскопия 117, 577 (2014). 
[29] Н.В. Сидоров, М.Н. Палатников, А.А. Яничев, А.А. Габаин, О.В. Макарова, О.Ю. Пикуль. Кристаллография 59, 794 (2014).

[30] V.S. Gorelik, N.V. Sidorov, A.I. Vodchit. Phys. Wave Phenomena 25, 10 (2017).

[31] J. Kasprzak, M. Richard, S. Kundermann, A. Baas, P. Jeambrun, J.M.J. Keeling, F.M. Marchetti, M.H. Szymańska, R. André, J.L. Staehli, V. Savona, P.B. Littlewood, B. Deveaud, Le Si Dang. Nature 443, 409 (2006).

[32] В.Б. Тимофеев. ФТП 46, 865 (2012).

[33] В.И. Бредихин, М.Д. Галанин, В.Н. Генкин. УФН 110, 3 (1973).

[34] V.S. Gorelik. Acta Phys. Hung. A 26, 37 (2006).

[35] V.S. Gorelik. J. Russ. Laser Res. 27, 400 (2006).

[36] V.S. Gorelik. Laser Phys. 18, 1479 (2008). 